\title{
Air-Injection Field Tests to Determine the Effect of a Heat Cycle on the Permeability of Welded Tuff
}

\author{
Kenrick H. Lee and Tzou-Shin Ueng
}

This is an informal report intended primarily for internal or limited external distribution. The opinions and conclusions stated are those of the author and mav or mav not be those of the Laboratory.

Work performed under the auspices of the U.S. Department of Energy by the

Lawrence Livermore National Laboratory under Contract W-7405-Eng-48. 


\section{DISCLAIMER}

This document was prepared as an account of work sponsored by an agency of the United States Government. Neither the United States Government nor the University of California nor any of their employees, makes any warranty, express or implied, or assumes any legal liability or responsibility for the accuracy, completeness, or usefulness of any information, apparatus, product, or process disclosed, or represents that its use would not infringe privately owned rights. Reference herein to any specific commercial products, process, or service by trade name, trademark, manufacturer, or otherwise, does not necessarily constitute or imply its endorsement, recommendation, or favoring by the United States Government or the University of California. The views and opinions of authors expressed herein do not necessarily state or reflect those of the United States Government or the University of California, and shall not be used for advertising or product endorsement purposes.

Prepared by Yucca Mountain Site Characterization Project (YMP) participants as part of the Civilian Radioactive Waste Management Program. The YMP is managed by the Yucca Mountain Site Characterization Project Office of the U.S. Department of Energy, Las Vegas, Nevada. 


\title{
Air-Injection Field Tests to Determine the Effect of a Heat Cycle on the Permeability of Welded Tuff
}

\author{
Kenrick H. Lee and Tzou-Shin Ueng
}

UCRL-ID--105163

DE92 000098

\begin{abstract}
As part of a series of prototype tests conducted in preparation for site characterization of the potential nuclear-waste repository site at Yucca Mountain, Nevada, air-injection tests were conducted in the welded tuffs in G-Tunnel at the Nevada Test Site. The objectives were to characterize the permeability of the highly fractured tuff around a horizontal heater emplacement borehole, and to determine the effect of a heating and cooling cycle on the rock-mass permeability. Air was injected into packed-off intervals along the heater borehole. The bulk permeability of the rock adjacent to the test interval and the aperture of fractures intersecting the interval were computed from the air-flow rate, temperature, and pressure at steady state. The bulk permeability of intervals along the borehole varied from a minimum of $0.08 \mathrm{D}$ to a maximum of over $144 \mathrm{D}$ and the equivalent parallel-plate apertures of fractures intersecting the borehole varied from 70 to $589 \mu \mathrm{m}$. Higher permeabilities seemed to correlate spatially with the mapped fractures. The rock was then heated for a period of 6.5 months with an electrical-resistive heater installed in the borehole. After heating, the rock was allowed to cool down to the ambient temperature. The highest borehole wall temperature measured was $242^{\circ} \mathrm{C}$. Air injection tests were repeated following the heating and cooling cycle, and the results showed significant increases in bulk permeability ranging from 10 to $1830 \%$ along the borehole.
\end{abstract}




\section{Introduction}

The Department of Energy's (DOE) Yucca Mountain Site Characterization Project Office (YMPO) is investigating the suitability of a site at Yucca Mountain, Nevada, for permanent disposal of highlevel radioactive waste and spent fuel. The YMPO has assigned Lawrence Livermore National Laboratory (LT.NL) the task of designing the waste packages, and of assessing the expected performance of the engineered barrier system in the repository environment. LLNL plans to conduct Engineered Barrier System Field Tests (EBSFT) in an Exploratory Study Facility (ESF) that will be constructed at Yucca Mountain as part of an extensive site characterization effort. The tests will include the use of electrical heaters to simulate the thermal loading expected from emplacement of high-level radioactive waste. Results from the EBSFT will be used, together with laboratory studies and numerical simulations, to assess the behavior of the repository environment with which the waste packages will interact.

Prior to the EBSFT at Yucca Mountain, we conducted the Prototype Engineered Barrier System Field Tests (PEBSFT) in G-Tunnel at the Nevada Test Site (NTS). The objectives of the PEBSFT were to (1) investigate the thermohydrologic, thermomechanical, and geochemical processes in fractured, porous, densely welded tuff; (2) evaluate the effectiveness of various measurement techniques and instrumentation for monitoring the hydrologic and thermomechanical rock responses under realistic conditions; and (3) develop procedures for the investigation to be performed in the EBSFT at Yucca Mountain (Ramirez and Wilder, 1990).

G-Tunnel is located in the Grouse Canyon tuff formation. The PEBSFT were performed within highly fractured, welded tuff with properties believed to be similar to the tuffs of the potential repository horizon in Yucca Mountain (Zimmerman and Finley, 1986). The tests were carried out in a section of the tunnel referred to as the G-Tunnel Underground Facility (GTUF). Figure 1 shows a plan view of the borehole layout. The test area is bounded by the Small Diameter Heater Alcove and the Rock Mechanics Incline. A 30.5-cm (12-in.) horizontal heater emplacement borehole was drilled to a depth of $10.7 \mathrm{~m}$. A 3-m long heater element was placed inside the borehole with its midpoint positioned at $8.5 \mathrm{~m}$ from the collar. A heating power level of about $3.2 \mathrm{~kW}$ was maintained for 128 days. The power was then ramped down to zero over a 67 -day period. The highest borehole wall temperature measured was $242^{\circ} \mathrm{C}$. Twelve instrumentation boreholes of 60.3 and $76 \mathrm{~mm}$ in diameter were also drilled to monitor the rock temperature, moisture content, and other hydrothermal parameters. All instrumentation boreholes were grouted after drilling. The PEBSFT are described in more detail by Ramirez and Wilder (1990).

As part of the PEBSFT in G-Tunnel, we conducted single-borehole air injection tests to characterize the in-situ permeability of the fractured tuff around the heater emplacement borehole, and to determine the effect of a heating and cooling cycle on the rock mass permeability. We made a number of measurements to determine the bulk permeability along packed-off sections of the borehole prior to heating the rock mass. We repeated these measurements following a heating and cooling cycle, permitting a direct comparison of the preheating and postheating borehole permeability profiles. Airinjection data were correlated with fracture-mapping data to estimate the equivalent parallel-plate apertures of fractures intersecting the borehole.

\section{Field Testing Program}

\section{Apparatus}

Figure 2 shows the arrangement of the G-Tunnel air permeability testing equipment. The straddle packer assembly, composed of three inflatable packers, was fitted to a $51-\mathrm{mm}$ aluminum pipe. Each packer had a seal length of $43 \mathrm{~cm}$ and an uninflated diameter of $27.9 \mathrm{~cm}$. The length of the borehole test zone straddled between two packers was $36 \mathrm{~cm}$. A single $6.35-\mathrm{mm}$ line was used to inflate all three 
packers to about $689 \mathrm{kPa}$ with nitrogen supplied from a cylinder. When the packers were inflated, the assembly isolated three zones in the 30.5 -cm borehole. Air was injected through separate $25-\mathrm{mm}$ lines leading to the isolated zones. The temperature in each zone was measured with a Type $E$ thermocouple. The air pressure was transmitted through a plastic tube and measured with a pressure gage located outside the borehole. The thermocouple and the plastic tube were fitted to two ports provided at the back end of each packer. The thermocouple extension wires and the plastic tubes were fed through the aluminum pipe.

The compressed air from the G-Tunnel line flowed through an air filter and a pressure regulator before it entered a four-branch manifold. Each branch contained a flow meter capable of measuring a different range of flow rate. The manifold covered flow rates ranging from 0.5 to $6300 \mathrm{slm}$. The pressure regulator maintained a constant test-zone pressure as the flow rate $\mathrm{i}$ djusted to the steady-state condition. To determine the mass flow rate of a highly compressible fluid such as air, the thermodynamic character of the fluid expansion must be considered. Therefore, the temperature and pressure of air leaving the manifold were measured by an in-line thermocouple and a pressure gage before being transmitted to the isolated zones.

Pressures were read by pressure transmitters with an accuracy of $0.5 \%$ of full scaie. These transmitters provided mechanical readings as well as electrical signals for automatic recording. Variable area flow meters measured flow rates with an accuracy and repeatability of 2 and $0.5 \%$ of full scale, respectively. Calibrations of the pressure gages, flow meters, and thermocouples were performed before and after field testing. Temperatures and pressures measured in the manifold and isolated test zones were recorded by the data acquisition system (DAS).

\section{Testing Procedures}

The packer assembly was first placed in the deepest location-about $30 \mathrm{~cm}$ from the bottom of the borehole. To secure the packer assembly, the aluminum pipe was attached to rock bolts adjacent to the borehole collar. We then inflated the packers to isolate three zones in the borehole: Zone 1, between the central packer and the packer nearest the borehole collar; Zone 2, between the central packer and the deepest packer; and Zone 3, behind the deepest packer. Zones 1 and 2 each had a fixed length of $36 \mathrm{~cm}$, while the length of Zone 3 varied with the location of the packer assembly.

Compressed air was injected into Zone 2 at three to five different steady-state pressures ranging from about 14 to $207 \mathrm{kPa}$, followed by similar injections into Zone 3 . Zone 1 functioned only as an observation zone. To approximate steady-state conditions, air injection was continued until the observed flow rate and test zone pressure remained constant for at least $10 \mathrm{~min}$. The injection pressure was limited to a maximum value of about $207 \mathrm{kPa}$ to minimize the effects of fracture deformation and turbulence, which could introduce significant errors in the measurements. For borehole intervals that included very large fractures, it was not possible to establish steady-state pressures of more than a few $\mathrm{kPa}$ and, therefore, only one or two steady-state pressures were used.

During air injection, the flow rates and test zone pressures were recorded manually. In addition, the DAS recorded temperatures and pressures in the manifold and borehole zones automatically at 1-min intervals. When a test zone was pressurized, the remaining two zones served as observis tion zones. Pressures and temperatures were monitored in observation zones to warn of any air leakage around or through the packers.

When one packer assembly location was completely tested, the assembly was moved outward about $25 \mathrm{~cm}$ and tests on Zones 2 and 3 were repeated. This sequence was repeated until a length of about $4.5 \mathrm{~m}$, measured frum the bottom of the borehole, was completely tested. 


\section{Data Analysis}

The use of fluid injection for bulk permeability tests in fractured rock assumes that the scale of the fractures is small relative to the scale of measurement, so that an equivalent continuum analysis is justified. For gas flow through porous media, under both laminar and turbulent conditions, the appropriate flow equation is Forchheimer's quadratic equation, which in radial coordinates is (Katz et al., 1959)

$$
-\frac{d P}{d r}=\frac{\mu q}{k}+\beta \rho q^{2}
$$

where

$$
\begin{aligned}
& P=\text { gas pressure } \\
& r=\text { radial flow distance } \\
& \mu=\text { viscosity } \\
& q=\text { darcy velocity } \\
& k=\text { bulk permeability } \\
& \beta=\text { turbulence factor } \\
& \rho=\text { density. }
\end{aligned}
$$

The relevant continuity and constitutive equations are:

$$
Q_{m}=2 \pi r \rho q L
$$

and

$$
\rho=\frac{M P}{Z R T}
$$

where

$Q_{m}=$ mass flow rate

$L \quad=$ length of borehole interval

$M=$ molecular weight of gas

$Z \quad$ = gas compressibility factor (approximately 1.0 for the low pressures used here)

$R \quad$ = universal gas constant

$T=$ absolute temperature.

For steady-state radial and isothermal flow of a gas injected into a packed-off borehole interval, Eqs. (1), (2), and (3) can be used to derive the following equation from which the bulk permeability is obtained:

$$
\frac{\pi L M\left(P_{b}^{2}-P_{e}^{2}\right)}{\mu R T Q_{m} \ln \left(r_{e} / r_{b}\right)}=\frac{\beta Q_{m}\left(1 / r_{b}-1 / r_{e}\right)}{2 \mu \pi L \ln \left(r_{e} / r_{b}\right)}+\frac{1}{k}
$$

where $P_{b}$ is the borehole injection pressure, $r_{b}$ the borehole radius, and $r_{e}$ the effective radius, or radius at which the pressure returns to the ambient value $P_{e}$. 
Equation (4) may be rewritten in the form of a linear equation:

$$
Y=\beta X+\frac{1}{k}
$$

This linear relationship can be plotted to obtain the bulk permeability $k$ from the inverse of the intercept and the turbulence factor $\beta$ from the slope. Therefore, $k$ and $\beta$ can be determined for a borehole test interval by conducting steady-state injection tests at two or more injection pressures.

One practical difficulty in applying Eq. (4) to single-borehole fluid injection measurements is the need to measure two boundary pressures in the rock. The first boundary pressure is the injection pressure, which is easily measured in the packed-off borehole interval. The second boundary pressure is usually taken as the ambient fluid pressure, which for this test is barometric pressure. Therefore, an effective radius $r_{e}$, or radius of influence, must be estimated. Because the test area is bounded on one side by a wall of the Small Diameter Heater Alcove at a distance of $5 \mathrm{~m}$ from the heater-borehole axis (Fig. 2), we use $5 \mathrm{~m}$ as an estimate for $r_{e}$.

To make rough estimates of the apertures of fractures intersecting the heater borehole, we assume that the fractures behave like smooth, parallel plates oriented normal to the borehole axis. For $n$ fractures of equal aperture intersecting a borehole interval of length $L$, the aperture is

$$
e=\left(\frac{12 L k}{n}\right)^{1 / 3}
$$

\section{Results and Discussions}

The test data are tabulated in Appendix A: Table A1 lists the preheating data, and Table A2 lists the postheating data.

\section{Preheating Permeability Results}

Figure 3 shows bulk permeability values that were calculated from measurements along the length of the heater borehole, from $6.25 \mathrm{~m}$ to a total depth (TD) of $10.72 \mathrm{~m}$. Mapped fracture locations are also shown. The bar location and width represent the actual position and width of the test interval. The permeability varies from a minimum of $0.08 \mathrm{D}$ at a depth of $9.23 \mathrm{~m}$ to a maximum in excess of $144 \mathrm{D}$. We were unable to quantify the largest permeabilities, which occurred within intervals centered at depths of $6.73,7.48$, and $7.73 \mathrm{~m}$ in highly fractured zones. At these locations, flow rates in excess of $2800 \mathrm{sim}$ were generated by injection pressures of only a few $\mathrm{kPa}$. Therefore, we were unable to make at least two sufficiently distinct pressure measurements to allow application of Eq. (4) for bulk permeability determination. In general, we found that higher permeabilities correlated with mapped fractures.

Figure 4 shows estimates of the equivalent parallel-plate apertures of fractures along the borehole. Aperture estimates varied from a minimum of $70 \mu \mathrm{m}$ at a depth of $9.23 \mathrm{~m}$ to a maximum of about $589 \mu \mathrm{m}$ at a depth of $6.98 \mathrm{~m}$. As with the bulk permeability results, measurements made in the highly fractured zones could not be used to estimate apertures. Figure 4 shows fracture aperture estimates at some test intervals along the borehole where no fractures are mapped. Since the matrix permeability of the rock is on the order of microdarcys (Lin and Daily, 1984), it appears that the resolution of the television-camera mapping of fractures (Ramirez and Wilder, 1989) accounted only for relatively major features; the mapping omitted smaller fractures that allowed substantial flows in some intervals. For these intervals with no mapped fractures, an equivalent single fracture aperture was computed. One such borehole interval, centered at $9.23 \mathrm{~m}$, yielded the minimum aperture of the profile. 


\section{Effect of Heating and Cooling Cycle}

The heating and cooling cycle resulted in some significant increases in bulk permeability along the borehole. In Table 1 and Fig. 5, the borehole permeability profile prior to heating is compared with the profile following the heating and cooling cycle. Because the measurement system could not adequately measure the high permeabilities of the test intervals centered at $6.73,7.48$, and $7.73 \mathrm{~m}$, we were unable to make any meaningful comparisons at these three intervals. The computed permeability increases varied from $10 \%$ to more than one order of magnitude. Figure 6 shows the percentage increase as a function of depth along the borehole. The maximum increase is $1830 \%$ at a depth of $8.98 \mathrm{~m}$. Higher percent increases in permeability seem to occur closer to the midpoint of the heater axis, implying that sections of the rock mass that are heated to higher temperatures show larger percent permeability increases. However, the higher relative increases also occur in the intervals of lower initial permeability, most of which were also located closer to the midpoint of the heater axis.

Table 1. Comparison of preheating and postheating bulk permeability values.

\begin{tabular}{cccccc}
\hline $\begin{array}{c}\text { Zone } \\
\text { no. }\end{array}$ & $\begin{array}{c}\text { Interval } \\
(\mathrm{m})\end{array}$ & $\begin{array}{c}\text { Interval } \\
\text { center } \\
(\mathrm{m})\end{array}$ & $\begin{array}{c}\text { Preheating } \\
\text { permeability } \\
(\mathrm{D})\end{array}$ & $\begin{array}{c}\text { Postheating } \\
\text { permeability } \\
(\mathrm{D})\end{array}$ & $\begin{array}{c}\text { Permeability } \\
\text { increase } \\
(\%)\end{array}$ \\
\hline & & & & & \\
2 & $9.69-10.05$ & 9.87 & 1.29 & 1.78 & 38 \\
2 & $9.30-9.66$ & 9.48 & 4.77 & 6.46 & 35 \\
2 & $9.05-9.41$ & 9.23 & 0.08 & 0.77 & 856 \\
2 & $8.80-9.16$ & 8.98 & 0.10 & 1.93 & 1830 \\
2 & $8.55-8.91$ & 8.73 & 1.89 & 5.57 & 677 \\
2 & $8.30-8.66$ & 8.48 & 0.62 & 4.82 & 635 \\
2 & $8.05-8.41$ & 8.23 & 0.51 & 3.75 & 728 \\
2 & $7.80-8.16$ & 7.98 & 1.22 & 10.10 & 98 \\
2 & $7.05-7.41$ & 7.23 & 2.87 & 179.00 & 24 \\
2 & $6.80-7.16$ & 6.98 & 144.00 & 237.00 & 115 \\
2 & $6.25-6.61$ & 6.43 & 110.00 & 1.24 & 18 \\
3 & $10.49-10.73$ & 10.61 & 1.05 & 1.71 & 10 \\
3 & $10.09-10.73$ & 10.41 & 1.55 & & 65 \\
\hline
\end{tabular}

To determine any possible effects of the repeatability of the measurements on comparisons between preheating and postheating results, air-injection measurements were repeated at six borehole locations and deviations in bulk permeability were computed. Deviations ranged from 0.5 to $8.7 \%$. The maximum deviation is quite small relative to the large permeability changes observed following the heating and cooling cycle.

\section{Discussion}

The reasons for the observed increases in permeability along the heater borehole are unclear; however, we can suggest a few possible mechanisms. Thermal expansion might have caused some relative movement or shearing across the fracture surfaces. For a fracture of significant roughness, such movement would result in some dilation as surfaces ride up asperities causing an increase in the average fracture aperture. Contraction associated with cooling might have lessened the aperture increase but probably not enough to attain the original fit and return the aperture to its preheating value.

Thermally induced microfraciuring is another possible cause for the permeability increase; significant microcracking has been observed in granites heated above $200^{\circ} \mathrm{C}$ (Wang et al., 1989). Thermally 
induced microfracturing could have created new fractures and propagated existing fractures. However, since the bulk permeability of this welded tuff is dominated by larger fractures, it is doubtful that microfracturing could have been the major mechanism responsible for the observed large increases in permeability.

Dehydration of clay minerals might have also contributed to the permeability increase. Although no attempt was made to analyze the filling material from fractures that were logged from the heater and instrument boreholes, we know that smectites are present in small to moderate amounts $(1-10 \%)$ in virtually all stratigraphic units in Yucca Mountain (Bish, 1985). If a significant amount of clay was present in the fractures tested in G-Tunnel, then clay dehydration could have resulted in an increase in average fracture void volume and, therefore, an increase in bulk permeability of the rock.

Finally, a higher water saturation in the fractures prior to heating, compared with the water saturation following the heat cycle, has the potential to cause an apparent permeability increase. However, when the matrix is partially saturated, the fractures are essentially dry because of the higher capillary suction forces in the matrix pores adjacent to the fractures (Klaveter and Peters, 1986). Therefore, it would seem that essentially all the drilling fluid pumped into the rock (drilling ended about two months before the beginning of permeability measurements) was either drained away through the predominantly vertical fractures or imbibed into the rock matrix.

\section{Conclusions and Recommendations}

The bulk permeability measured in intervals along the heater emplacement borehole showed a high degree of heterogeneity, varying from a minimum of $0.08 \mathrm{D}$ to a maximum of more than $144 \mathrm{D}$.

Equivalent parallel-plate hydraulic apertures of fractures intersecting the borehole varied from a minimum of $70 \mu \mathrm{m}$ to a maximum of about $589 \mu \mathrm{m}$. A comparison of borehole permeability profiles showed significant permeability increases ranging from 10 to $1830 \%$ as a result of the heating and cooling cycle.

In future tests, an attempt should be made to eliminate uncertainties concerning the possible effects of preheating and postheating fracture saturation differences. This can be accomplished by a third measurement of the borehole permeability profile, after a sufficiently long period is allowed for the rock to return close to the moisture conditions that existed during the preheating measurements. The rewetting process could be accelerated by flooding the borehole and then measuring the rock moisture content with either neutron gage or high frequency electromagnetic (HFEM) methods to determine when the preheating moisture conditions are reattained. 


\section{References}

Bish, D. L., and D. P. Vaniman (1985), Mineralogic Summary of Yucca Mountain, Nevada, Los Alamos National Laboratory, Los Alamos, NM, LA-10543-MS. NNA.870407.0330

Katz, D. L., D. Cornell, R. Kobayashi, F. H. Poettmann, J. A. Vary, J. R. Elenbaas, and C. F. Weinaug (1959), Handbook of Natural Gas Engineering, (McGraw-Hill, New York). NNA.900626.0212

Klavetter, E. A., and R. R. Peters (1986), Estimation of Hydrologic Properties of an Unsaturated, Fractured Rock Mass, Sandia National Laboratories, Albuquerque, NM, Report No. SAND84-2642. NNA.870317.0738

Lin, W., and W. Daily (1984), Transport Properties of Topopah Spring Tuff, Lawrence Livermore National Laboratory, Livermore, CA, UCRL-53602. NNA.891026.0025

Ramirez, A., and D. Wilder (Eds.) (1989), Prototype Engineered Barrier System Field Tests ('EBSFT), Progress Report Through November 1, 1988, Lawrence Livermore National Laboratory, Livermore, CA, UCID-21640. NNA.910207.0024

Ramirez, A., and D. Wilder (Eds.) (1991), Prototype Engineered Barrier System Field Tests (PEBSFT), Final Report, Lawrence Livermore National Laboratory, Livermore, CA, UCRL-ID106159. (Readily available)

Wang, H. F., B. P. Bonner, S. R. Carlson, B. J. Kowallis, and H. G. Heard (1989), "Thermal Stress Cracking in Granite," J. Geophys. Res. 94(B2), 1745-1758. NNA.910131.0265

Zimmerman, R. M., and R. E. Finley (1986), Summary of Geomechanical Measurements Taken in and Around the G-Tunnel Underground Facility, NTS, Sandia National Laboratories, Albuquerque, NM, Report No. SAND86-1015. HQS.880517.2366 


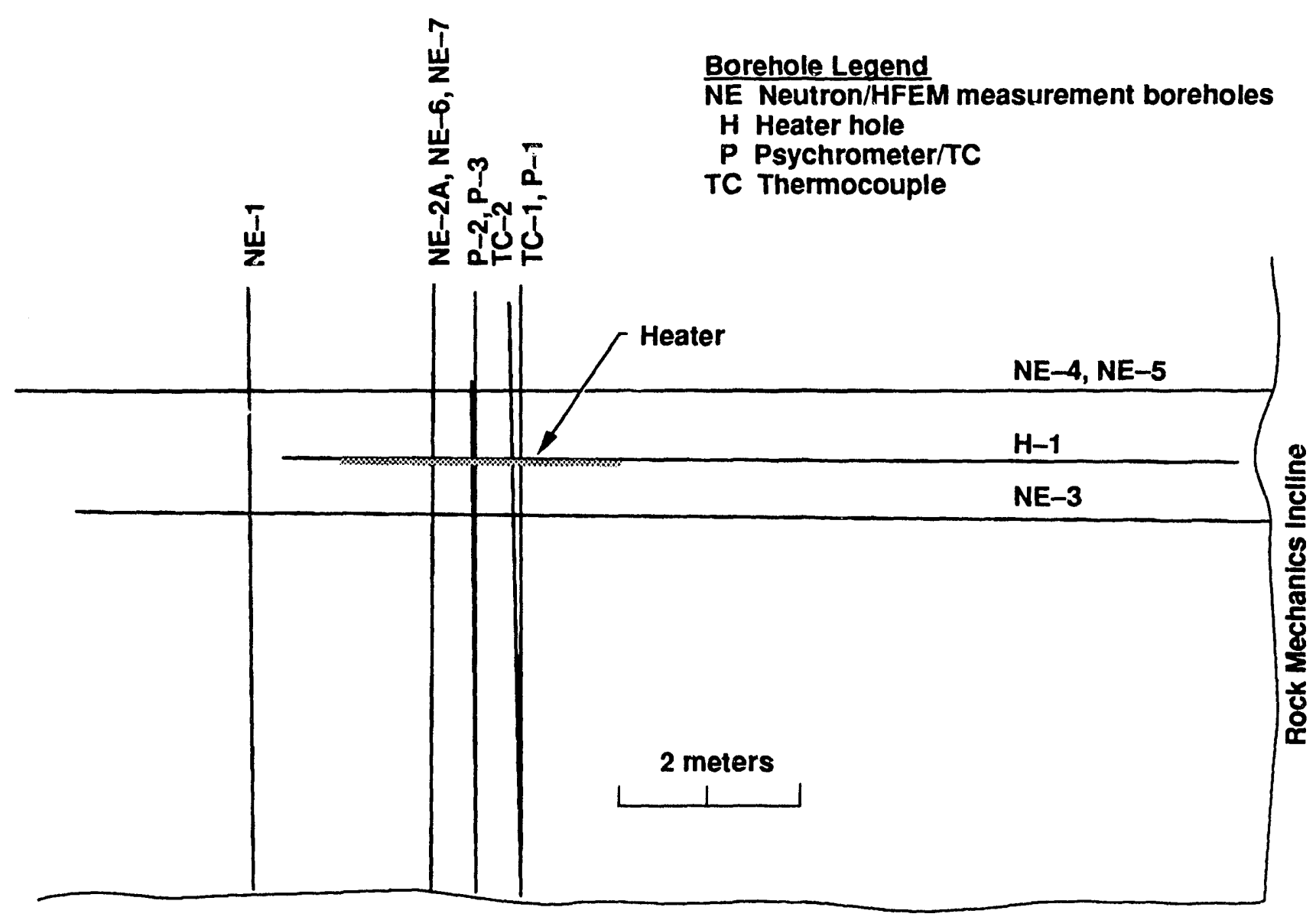

Small Diameter Heater Alcove

Figure 1. Plan view of the borehole layout. The location of the Rock Mechanics Incline and the Small Diameter Heater Alcove in G-Tunnel are shown for reference (Ramirez and Wilder, Eds., 1990). 


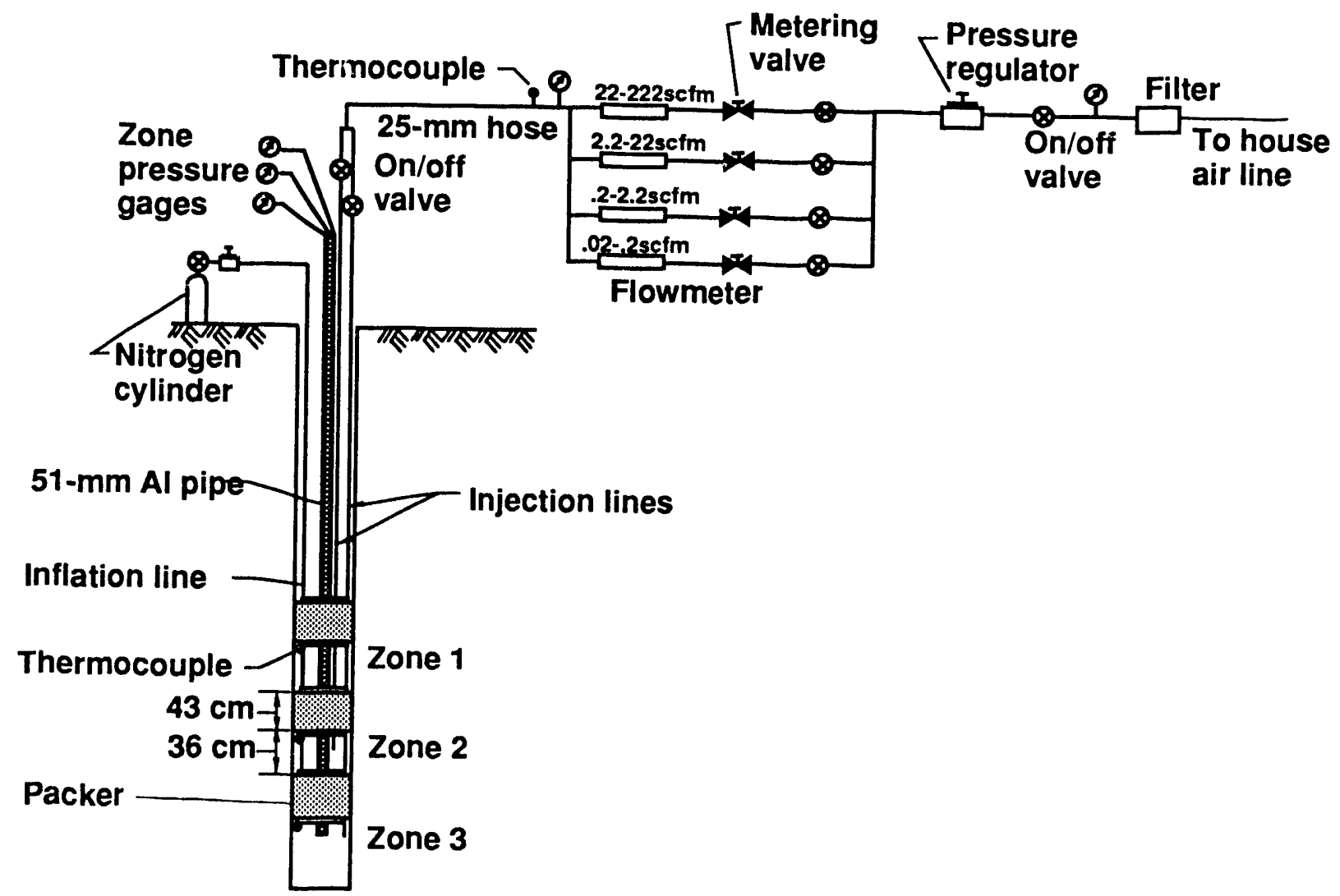

Figure 2. Schematic of gas permeability measurement apparatus. 


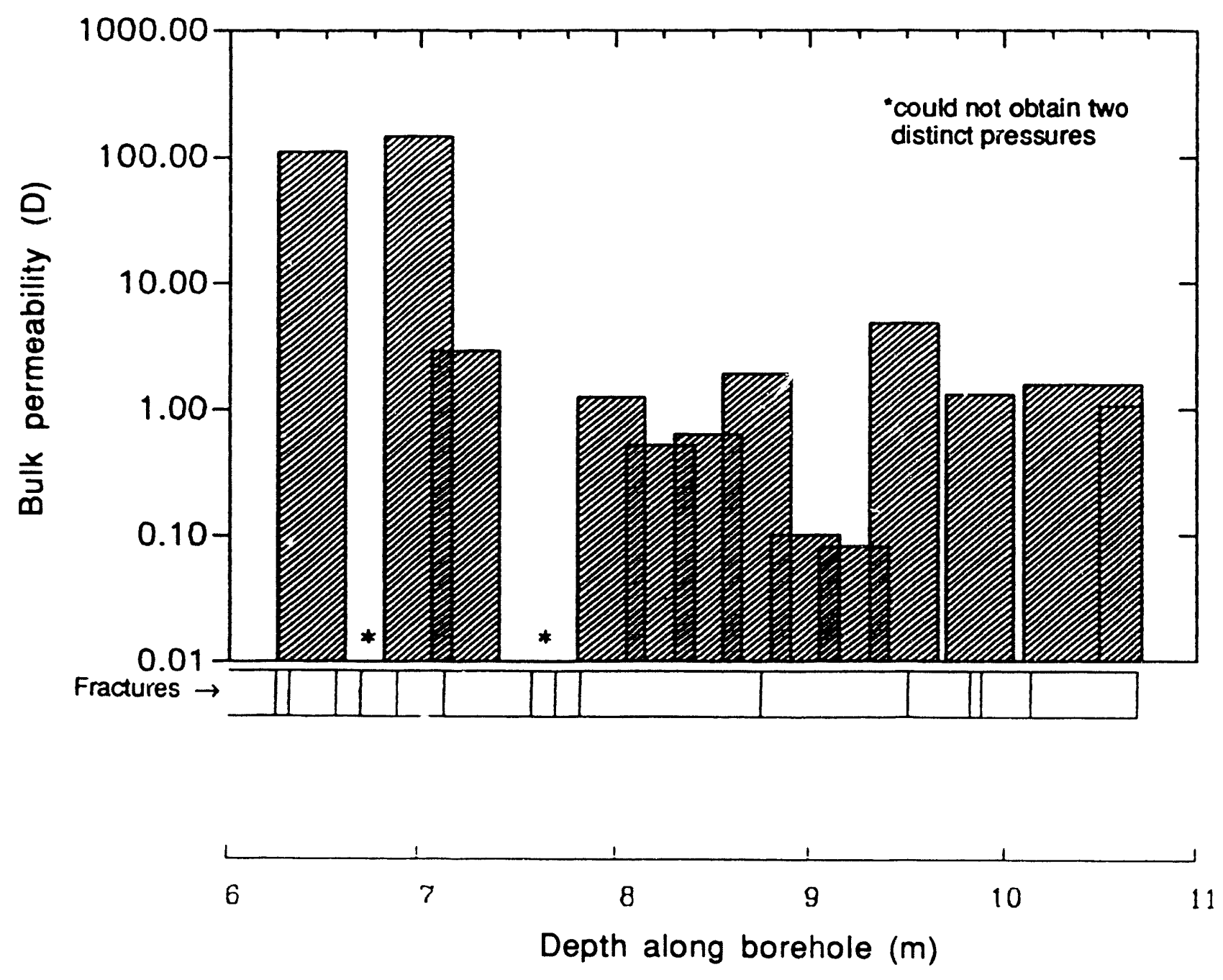

Figure 3. Preheating bulk permeability and mapped fracture locations between depths of 6.25 and $10.72 \mathrm{~m}$ along heater borehole. Bar width equals length of test interval. 


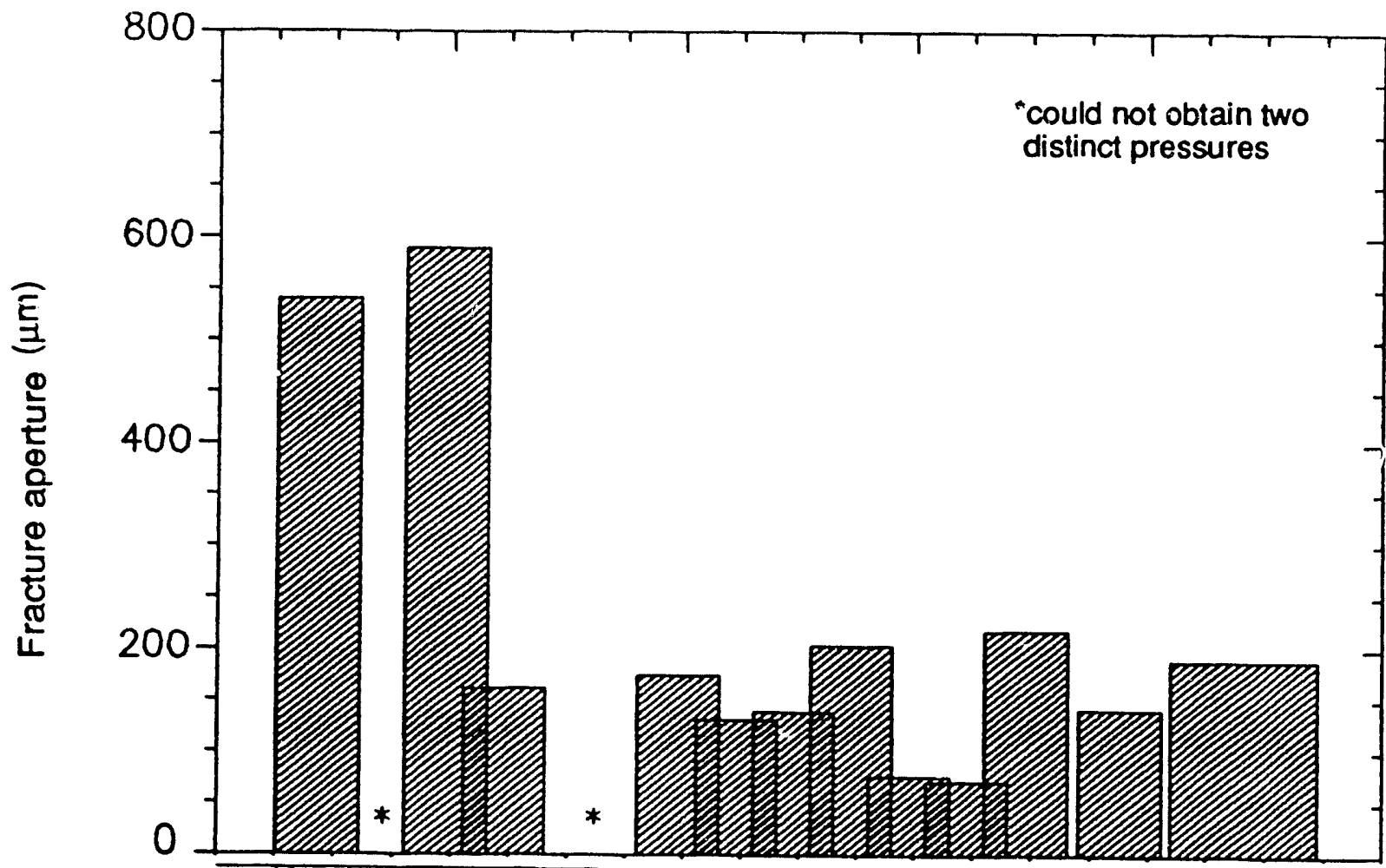

Fractures $\rightarrow$
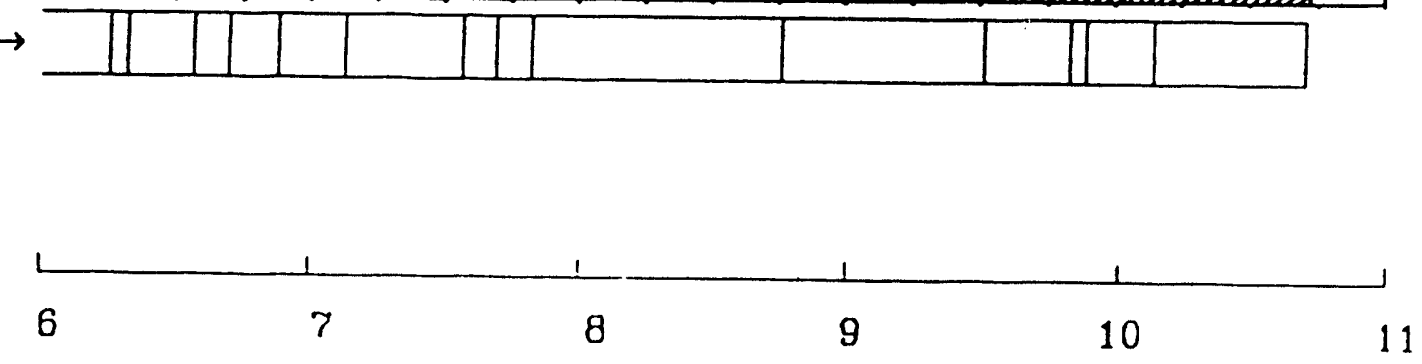

Depth along borehole $(\mathrm{m})$

Figure 4. Preheating fracture apertures and mapped fracture locations between depths of 6.25 and $10.72 \mathrm{~m}$ along heater borehole. Bar width equals length of test interval. 


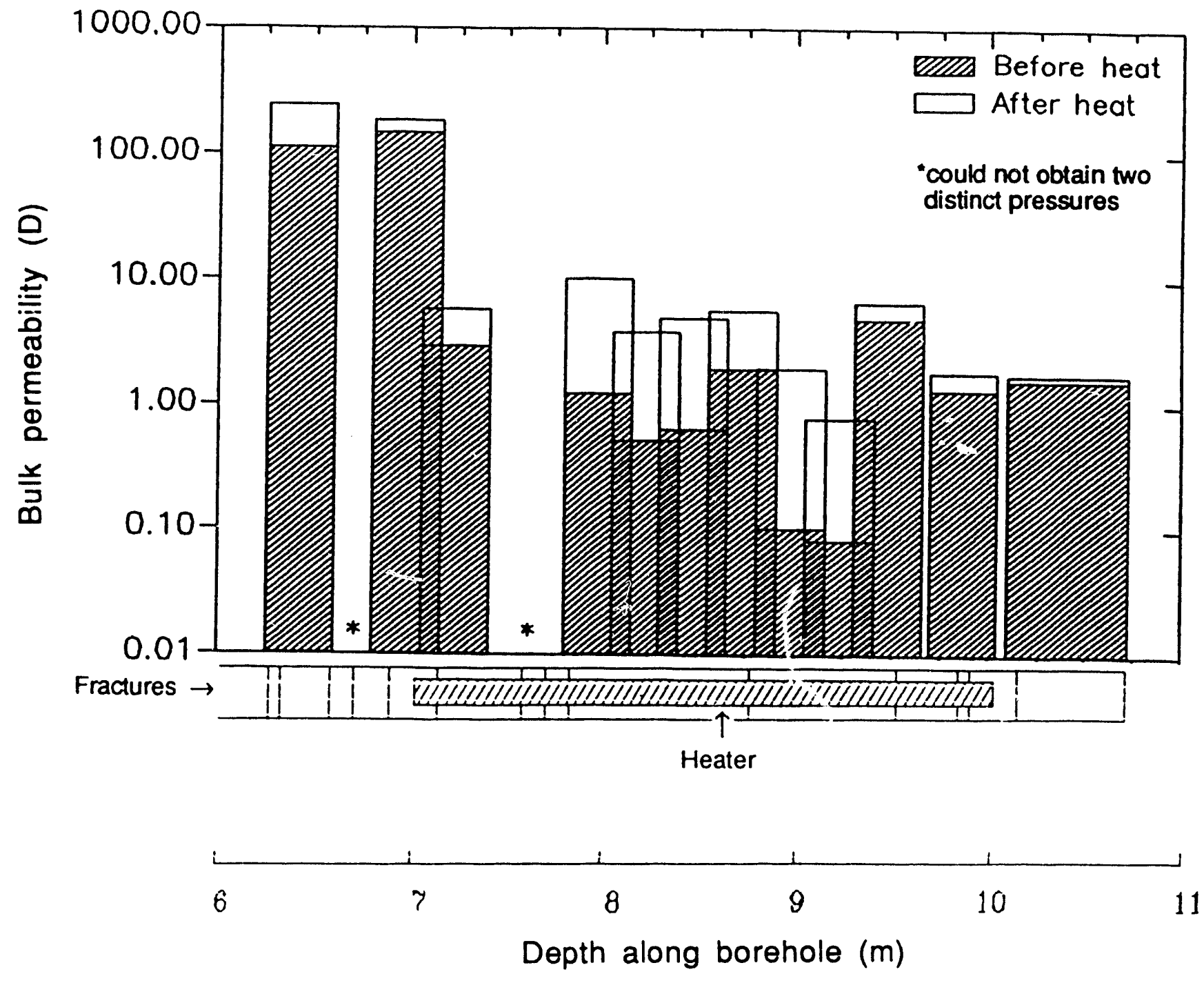

Figure 5. Comparison of preheating and postheating bulk permeability values along hizater borehole. Locations of heater and mapped fractures are indicated. Bar width equals length of test interval. 


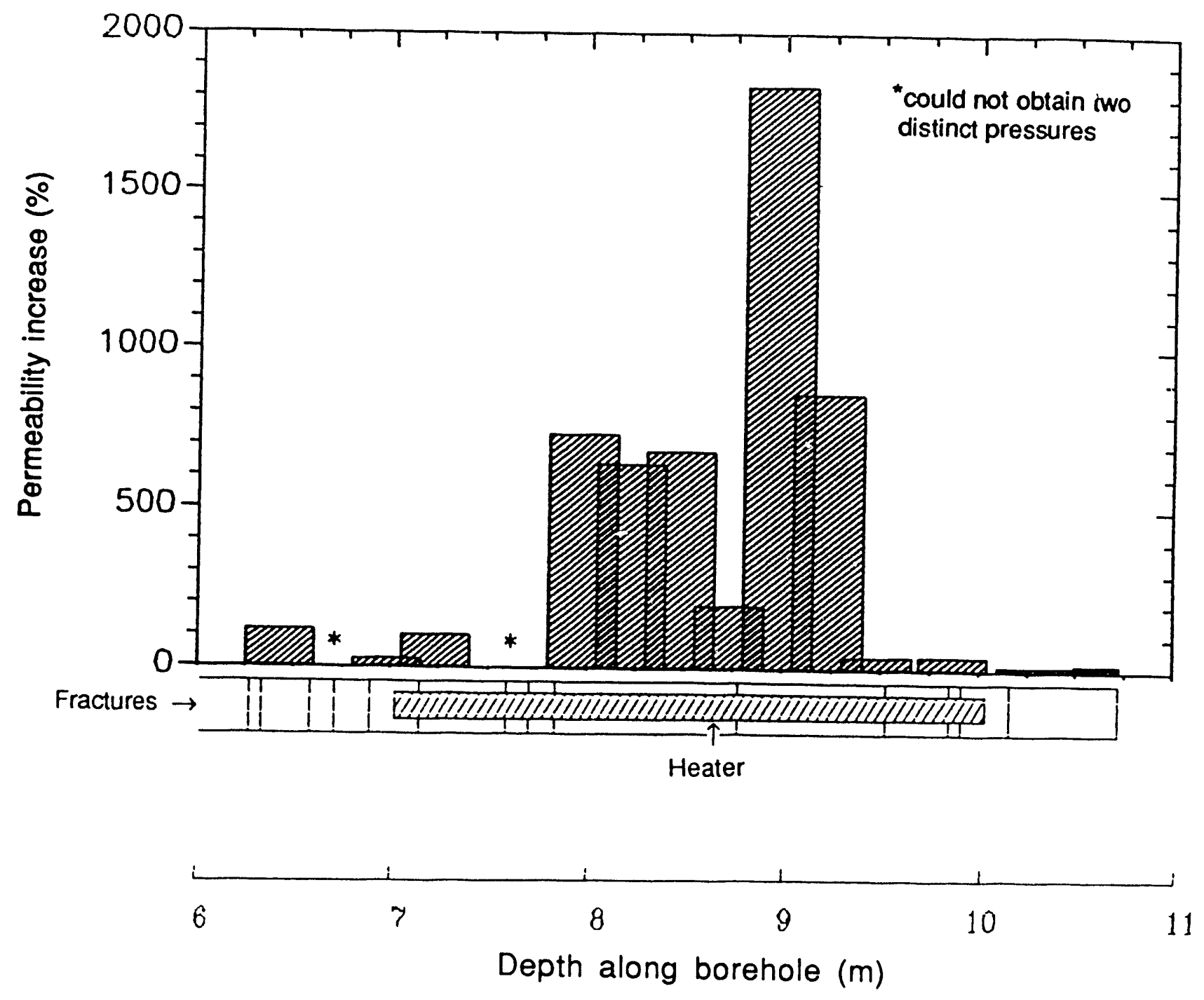

Figure 6. Percent bulk permeability increases following heat cycle. Locations of heater and mapped fractures are indicated. 


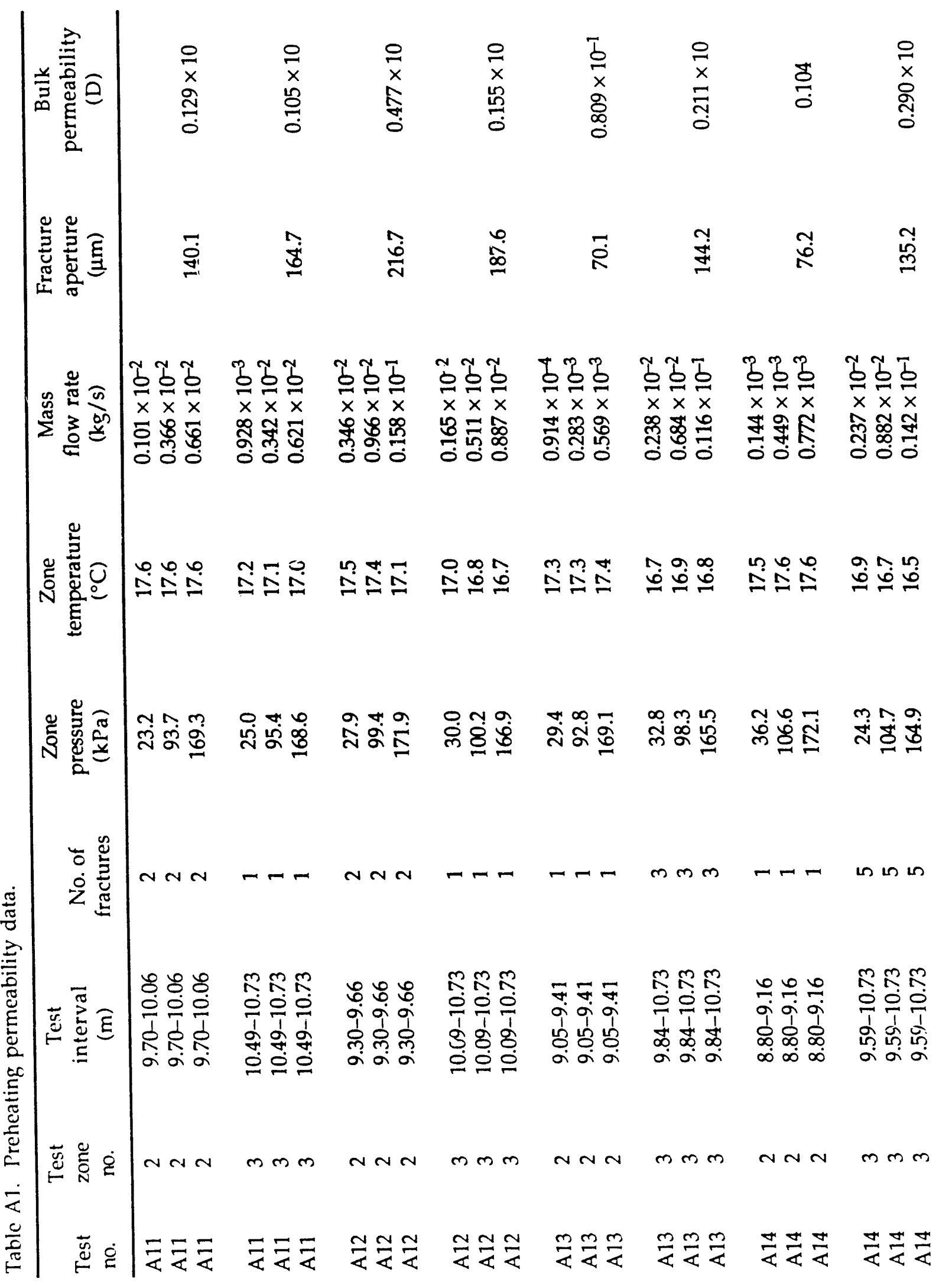




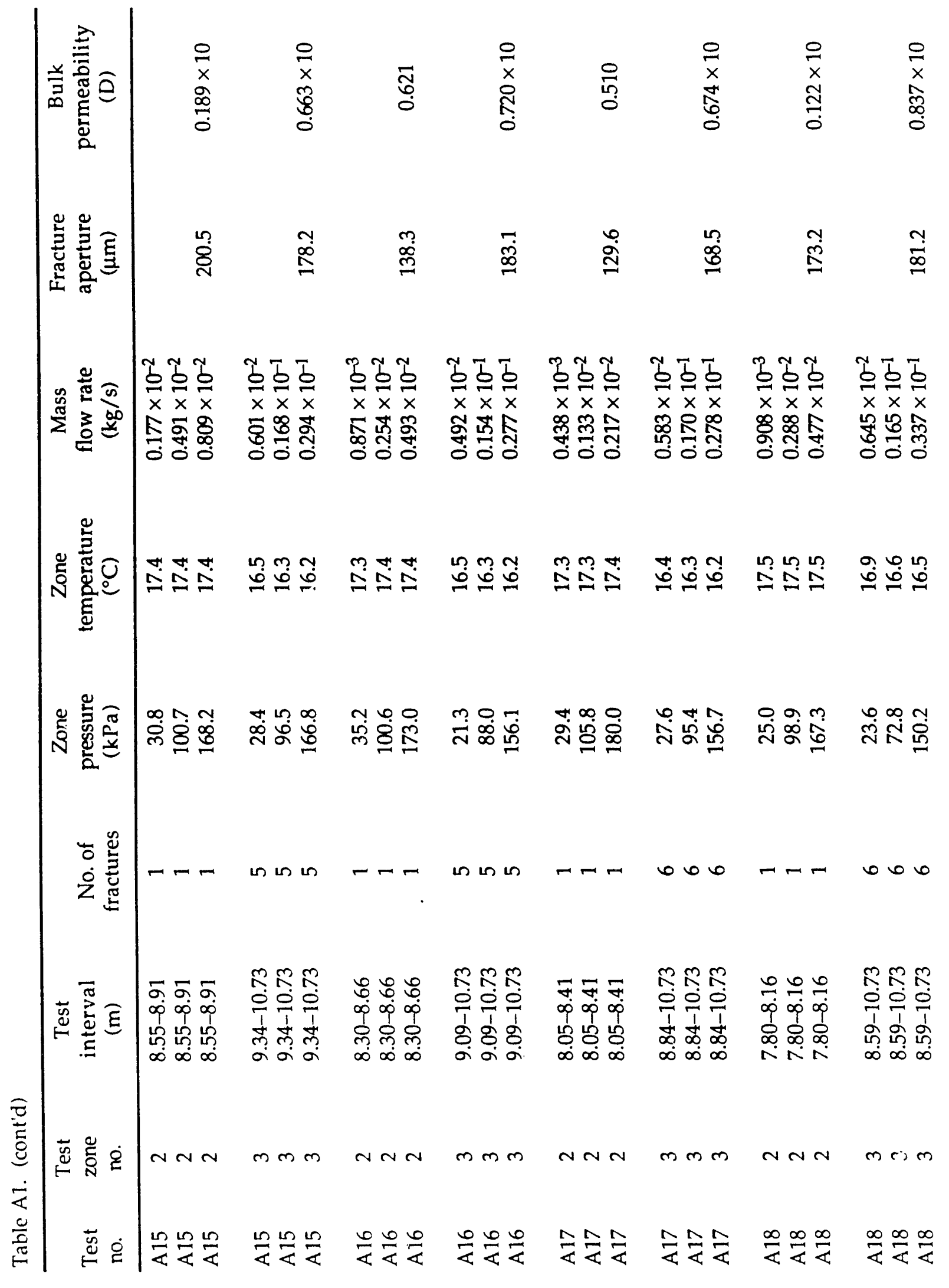




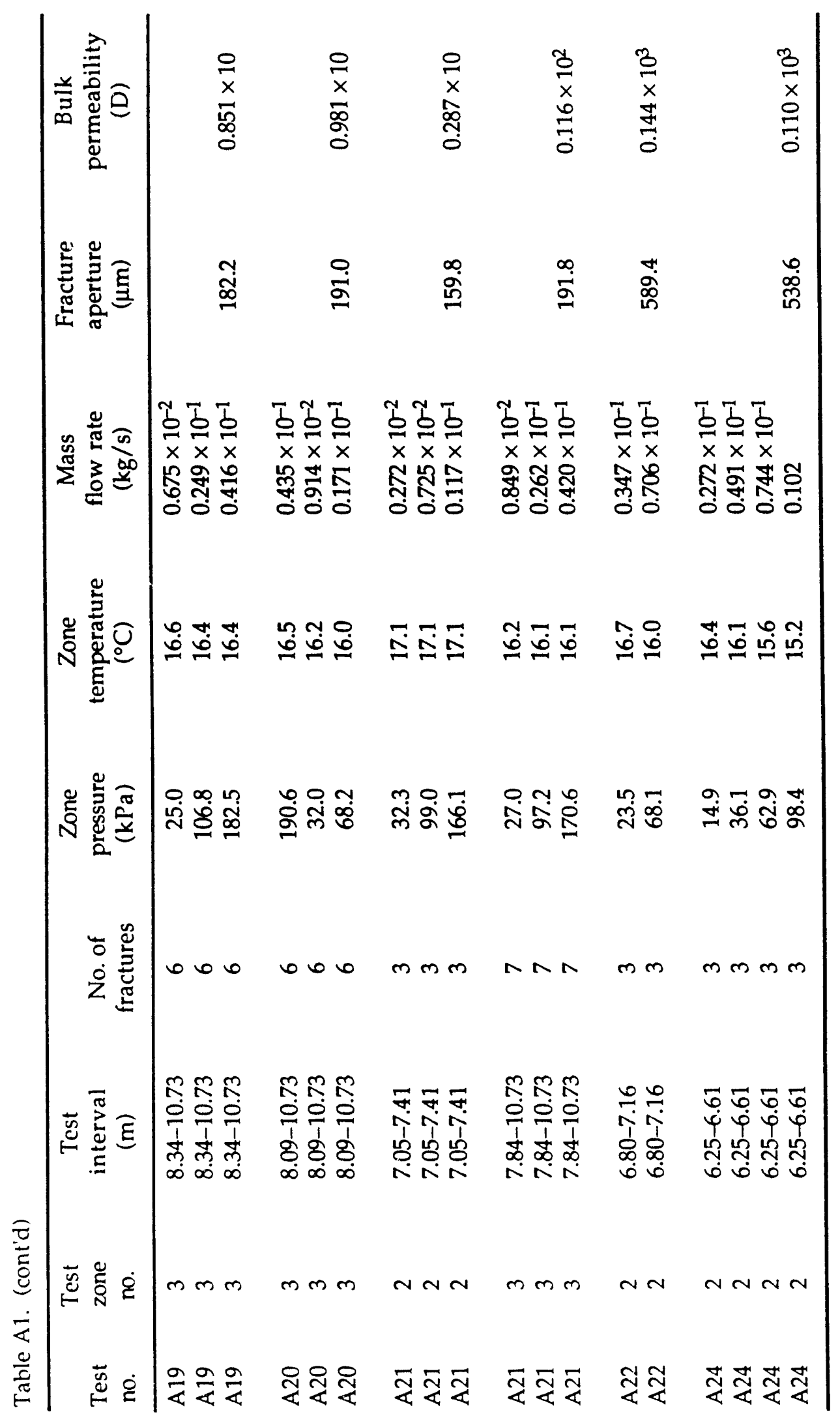




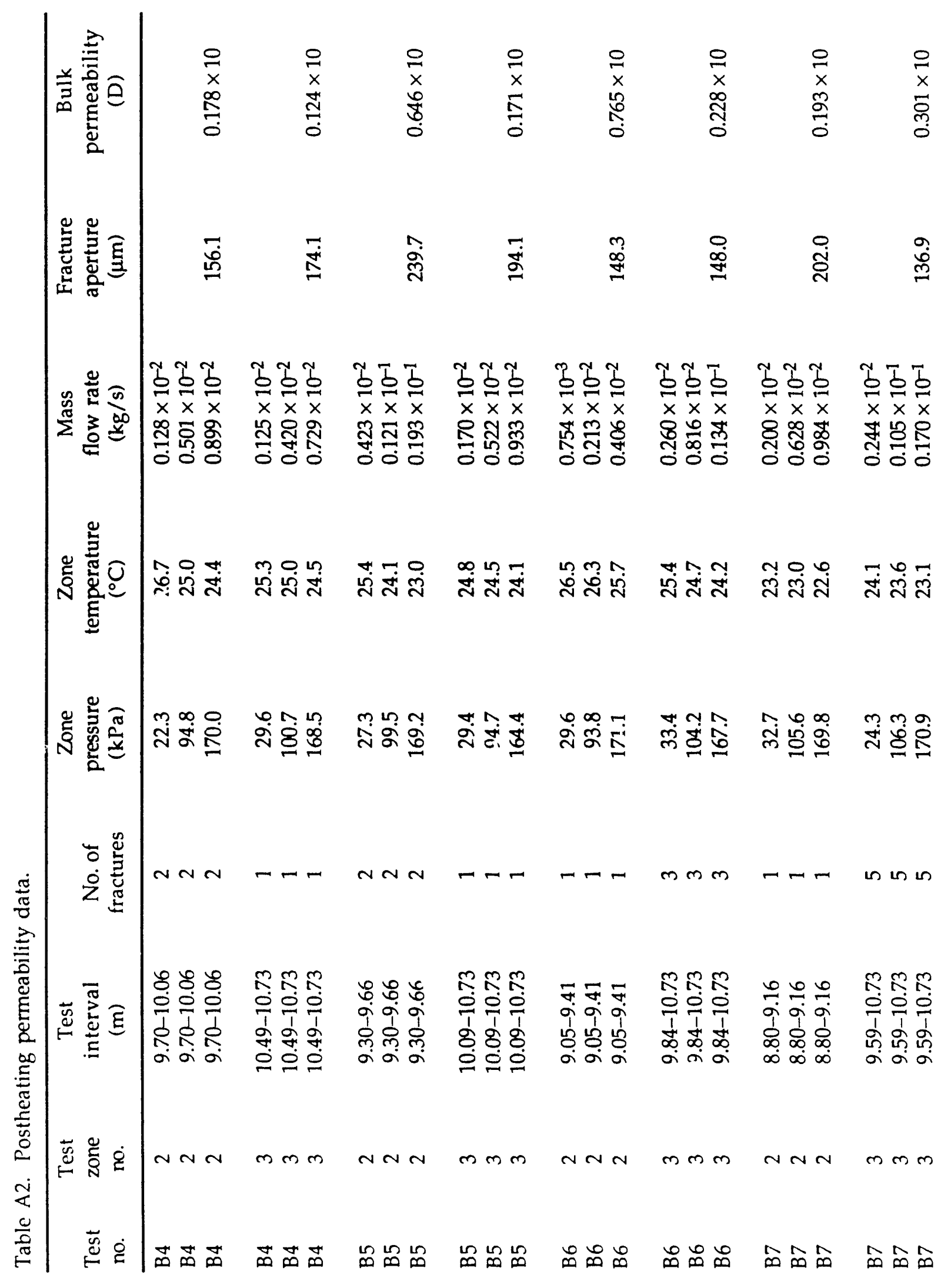




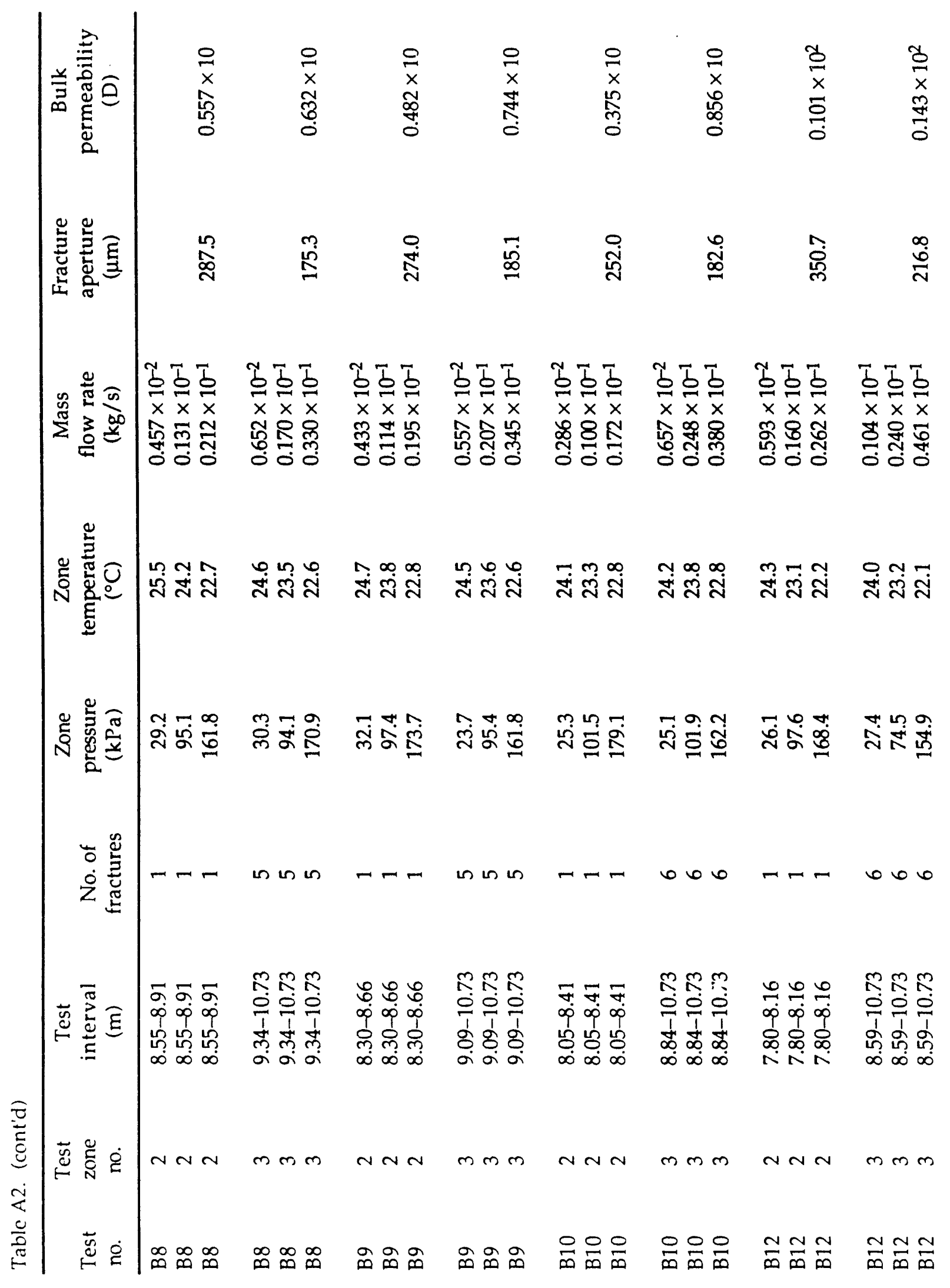




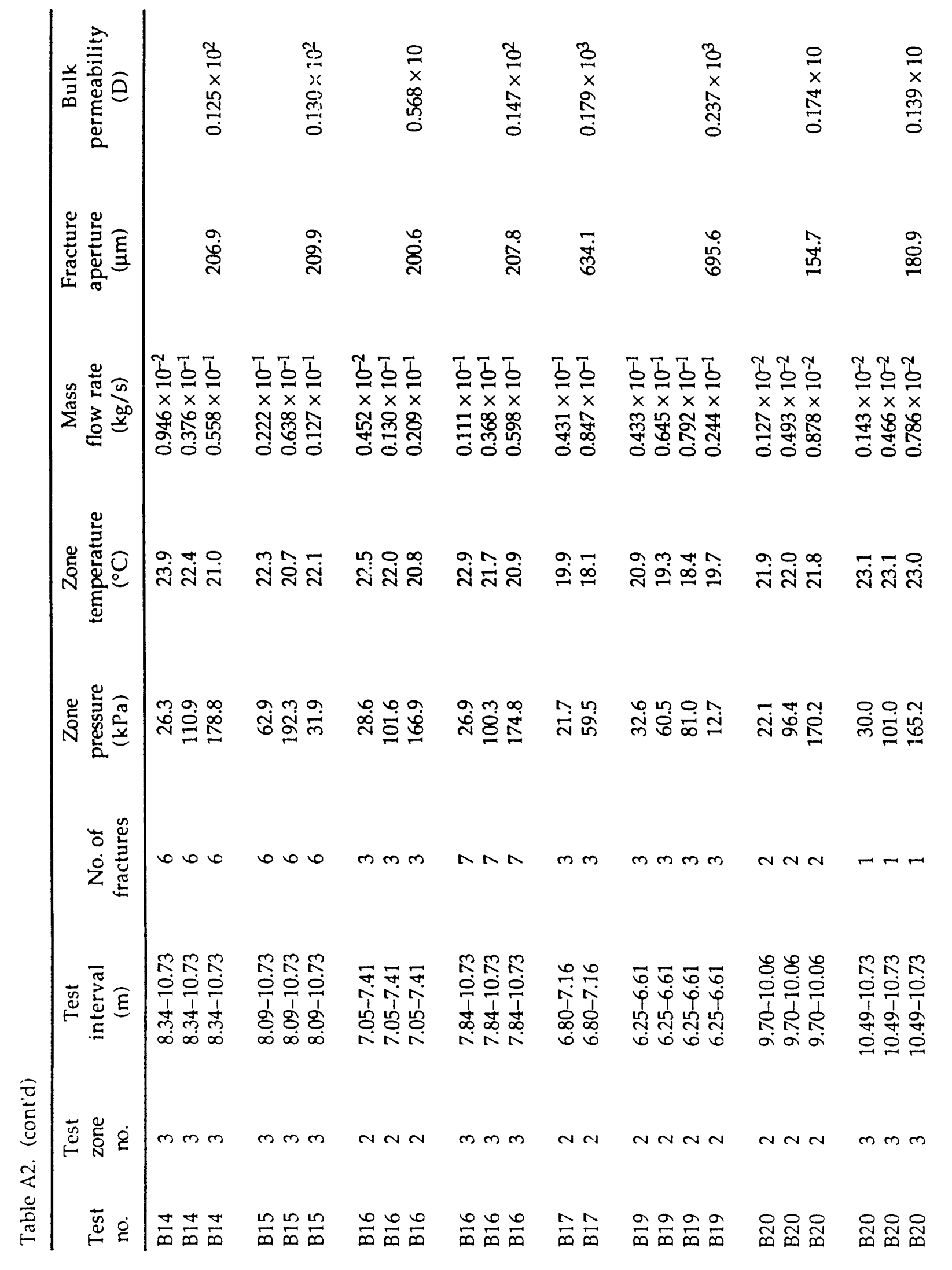




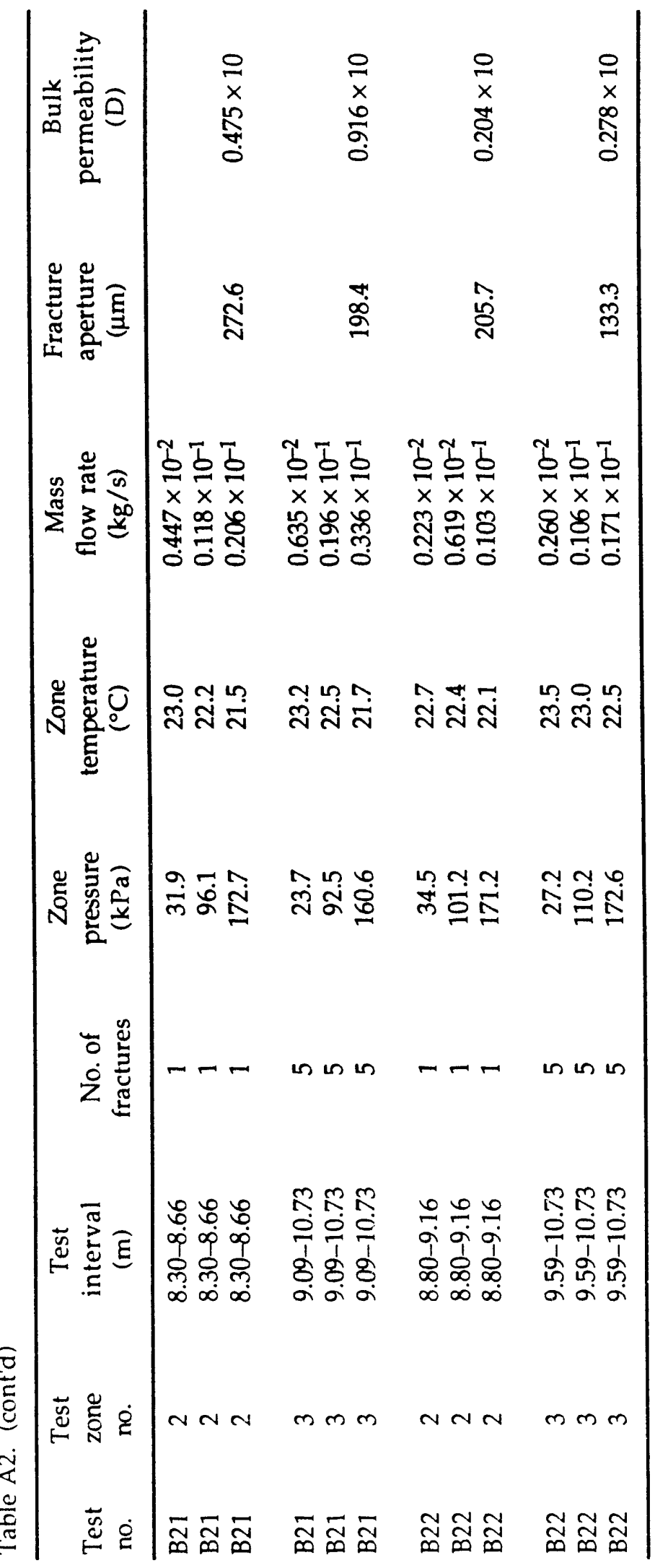


Appendix A

This report does not use any information from the Reference Information Base nor contain any candidate information for the Reference Information Base or the Site and Engineering Properties Data Base (SEPDB). 
NNA.910912.0001 

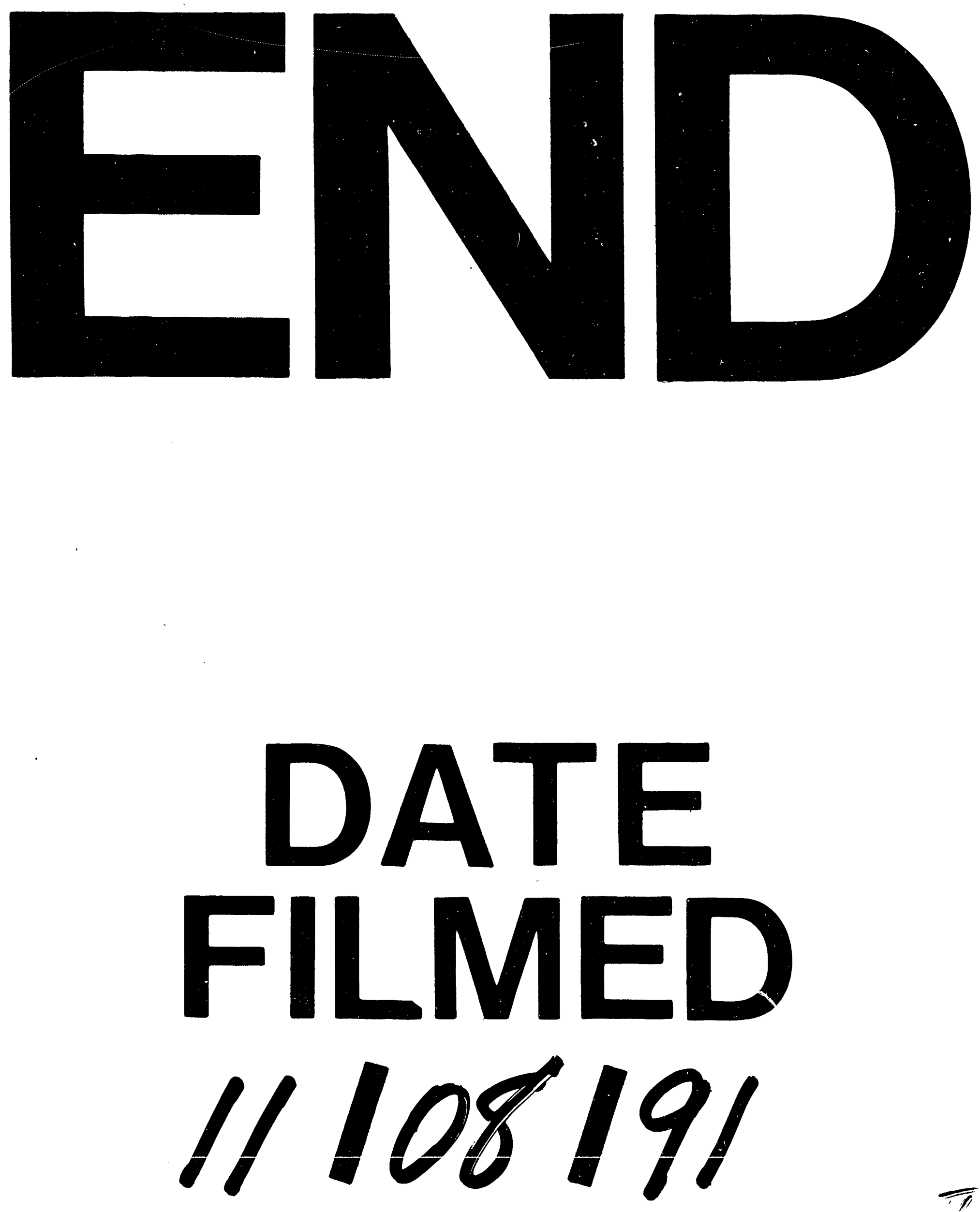

II: 